\title{
The Role of Urban Agriculture in Economic, Social and Environmental Sustainability in Africa
}

\author{
Lemi Gonfa \\ Lecturer, Department of Agricultural Economics, Wolaita Sodo University
}

\begin{abstract}
Synapse
The role of urban agriculture in socio-economic and environmental sustainability in Africa was reviewed in this seminar. The main objective of this paper was to reveal the role of urban agriculture in socio-economic and environmental sustainability in Africa. Different theoretical and empirical literatures conducted by most scholars were rectified that the benefits of urban agriculture is unarguable issue. Many scholars argue that urban agriculture played a paramount significant role in job creation, in access to balanced diet, in access to fresh milk, vegetables and fruit for urban dwellers. Urban agriculture is also part of the urban greenery that improves the urban micro-climate, increases biological diversity, as well as the aesthetics and recreational functions of urban areas. But there were still some other scholars that urban agriculture has negative externalities on metropolitan. According to theories and empirical studies, not easy access to land, lack of experience, lack of financial support, grazing of crops by animals and theft of farm products, low land productivity, lack of training, access to credit facilities and high interest rates were identified as the potential challenges for the development of urban agriculture. As a result of the numerous importance of this sector government and other non-government should initiate programmes in support of urban agriculture in order to overcome the aforementioned problems.
\end{abstract}

Keywords: urban agriculture

DOI: $10.7176 / \mathrm{JNSR} / 9-2-03$

\section{INTRODUCTION}

About half of the world population lives in urban areas. It is estimated that, by 2020, the developing countries will account for about $75 \%$ of all urban dwellers (Bakker et al., 2001). However, while urbanization brings a number of socio-economic benefits, the rapid increase in urban population leads in a number of challenges. Urban authorities find themselves heavily challenged in terms of their capacities to provide adequate services such as housing, infrastructure, facilities and employment. This takes place at a time when many cities are saddled with the challenge to tackle growing unemployment and poverty. Some cities have adopted urban agriculture as a strategy to address the increasing urban unemployment, poverty and hunger. This is because urban agriculture supports food security and nutrition, provides employment and generates income for the urban poor in general and the disadvantaged groups such as women, the disabled, the elderly and the unemployed youth.

According to Armar-Klemesu (2006), about 200 million urban dwellers in the world participate in urban farming and the sector provides about 800 million people with at least some of their food. Increases in urban agriculture have also been recorded in African cities such as Bissau (Guinea Bissau), Dakar (Senegal), Kumasi (Ghana), Lome (Togo), Nairobi (Kenya and Dares-Salame (Tanzania) [Food and Agricultural Organization (FAO), 2004]. Thus urban agriculture is, in most cases, a response by the urban poor to inadequate, unreliable and irregular access to food and to lack of purchasing power. Most cities, particularly in developing countries, are unable to generate sufficient income and employment for their rapidly growing populations. This translates directly into lack of food.

Bryceson and Potts (2005), and Mudimu (1996) argued that urban agriculture in Africa was evolved as a response to scant sources of urban economic sustenance i.e. insufficient supply of staple food to cities coupled with declining purchasing power of city dwellers. Consequently millions of urban dwellers are reinforced to restore farming in urban areas throughout many African cities either to supplement their household income or because they cannot afford to meet their daily food needs. (Balormakpani and Dinye, 2012) the recent trend of increasing urban agricultural activities in African towns and cities coupled with the contribution of the activity to development efforts of towns and cities has become a prominent issue.

According to Mpofu (2013) Ethiopia has a high rate of urbanization, averaging about 4.3\% per annum. Current urban population of 12 million will triple by 2030, reaching 32 million. This rapid growth will have a major impact on livelihoods, food security and the environment including in Addis Ababa. The City's population growth has been accompanied by growing unemployment, urban poverty and malnutrition. The Addis-Ababa City Government has recognized urban agriculture as one of the important tools to end poverty. There is now growing consensus that urban agriculture is not a problem, as previously thought, but an important contributor to sustainable urban growth and development, as well as to people's livelihoods.

Despite the fact that the growth and development of urban agriculture is an economically viable enterprise, official projects and programmes aimed at improving urban agriculture have been relatively rare. This is 
typically because urban agriculture has not been taken as an integral part of the urban planning process. Many authors wrote about the advents of urban agriculture and its wide spread existence in many cities of the world (RUAF 2007, Bryceson and Potts 2005, Bryld 2003, UNDP 1996, Mougeot 1994). They emphasized on urban resources that urban agriculture utilizes and their opportunity costs, realizing the fact that the resources (such as land) have also high demand for other urban uses (e.g. building houses). Yet, little has been said to justify the economic relevance of urban agriculture in cities. As a result its contribution towards income generation, employment creation, food security, poverty alleviation and environmental protection has remained negligible. The sector suffered from weakness in the institutional, financial and human capacities of the city. These included lack of a facilitating policy, unavailability of collateral, high cost of the requisite inputs, and the absence of extension services.

Research on the role that urban agriculture plays in livelihoods of urban people is, therefore, helpful for better understanding of the urban poor livelihood strategies and realizing its contribution in urban poverty alleviation. For instance, the Ministry of Finance and Economic Development for Ethiopia (2010/11) MoFED (2010/11) reported that the poverty gap between the urban and rural Ethiopia is narrowing, not because the poverty in the rural Ethiopia is reducing down to poverty levels in the urban areas, but it is because of the rise in the number of urban people below the poverty line (based on the country's standard) over time. The report also emphasized the unsatisfactory nation's urban development policies as major reasons for rise in the urban poverty. Thus, the motive behind carrying out this review is to improve the understanding that urban agriculture contributes to the livelihoods of urban society.

\subsection{Objectives of the Paper}

1. To reveal how urban agriculture had contributed to the socio-economic well-being of urban farmers;

2. To review major constraints that affect the development of urban agriculture

3. Propose measures that could lead to the sustained growth and development of urban agriculture

\subsection{Theoretical Review of Urban Agriculture Definitions and Concepts}

\subsubsection{What is urban agriculture?}

The phrase urban agriculture can refer to any agricultural activities, including crop cultivation, livestock, and aquaculture (fish farms) that take place in an urbanized area. Most of today's working definitions come from International Development Research Center (IRDC). In the book Cities Feeding People, published by IRDC in 1994, co-author Egziabher defined urban agriculture as the practice of food production within a city boundary or on the immediate periphery of a city - it includes the cultivation of crops, vegetables, herbs, fruit, flowers, orchards, parks, forestry, fuel wood, livestock, aquaculture, and bee-keeping.

An industry that produces, processes and markets food and fuel, largely in response to the daily demand of consumers within a town, city or metropolis, on land and water dispersed throughout the urban and peri-urban area, applying intensive production methods, using and reusing natural resources and urban wastes, to yield a diversity of crops and livestock (Smit et al. 1996).

Four years later in a review of definitions commissioned by the same institution, Mougeot defined urban agriculture as an industry located within (intra-urban) or on the fringe (peri-urban) of a town, a city or a metropolis, which grows and raises, processes and distributes a diversity of food and non-food products, (re)using largely human and material resources, products and services found in and around that urban area, and in turn supplying human and material resources, products and services largely to that urban area (Mougeot 2000).

\section{Types and characteristics of urban agriculture}

Zeeuw (2003) stated that one has to consider various aspects of urban agriculture in order to arrive at a definition that is meaningful in the local context: Types of product: Crops (grains, root crops, vegetables, mushrooms, fruits) or Animals (poultry, rabbits, goats, sheep, cattle, pigs, guinea pigs, fish, etc.) or combinations of these.

Non-food products like aromatic and medicinal herbs, ornamental plants, tree products (seed, wood, fuel, etc.), tree seedlings, etc. Types of economic activities: Purchasing, production and marketing (and also processing). Types of location: Cities (intra-urban) or in the periurban Homestead (on-plot) or on land away from the residence (off-plot), on private land (owned, leased) or on public land (parks, conservation areas, along roads, streams and railways), or semi-public land (schoolyards, grounds of schools and hospitals. Scales of production and technology used individual or family farms, group or cooperative farms and enterprises, micro-, small- and medium-sized enterprises, as well as large-scale undertakings. Types of actors: Urban poor, Women, children and every socioeconomic group of an urban area.

\subsubsection{Food Security, Nutrition and Health}

According to Smit et al. (2006) factors that influence the health and well-being of individuals include the quantity, quality, regularity, and nutritional balance of their food, as well as the quality of their living environment. Urban agriculture contributes to the health and well-being of a community by reducing hunger, strengthening access to food, improving nutrition, and improving environmental conditions that affect health. 
The benefits offered by urban agriculture are thus both quantitative and qualitative increasing food quantities reduces hunger, while improving food quality fosters better health and nutrition. Thus urban agriculture helps ensure children's access to food, enhances their health status, and contributes to empowering women. Urban agriculture has proven its contributions to urban and national food security countless times, most notably in recent years. As more frequent and more damaging disasters confront a population that is moving to the world's cities, urban farming often offered a critical solution. Food insecurity has most commonly been measured at the household or family level, where the hurdle to food security is most commonly access to good food. Access, compared to availability, implies that the family has either money or direct access through self-production or barter. The main health risks associated with urban agriculture can be Contamination of crops with pathogenic organisms as a result of irrigation with water from polluted streams and insufficiently treated wastewater or the unhygienic handling of the products during transport, processing and marketing of fresh products; Spread of certain human diseases by mosquitoes and scavenging animals attracted by agricultural activities; Contamination of crops due to prolonged intensive use of agrochemicals; Contamination of soils and products with heavy metals due to traffic emissions and industrial effluents; and Certain diseases transmitted to humans by keeping livestock in close proximity without proper precautions being taken.

\subsubsection{Social benefits}

The benefits of urban agriculture to farmers and their families are a springboard for its benefits to society. Urban farming improves social equity by improving the health and productivity of poorer populations and providing an opportunity to earn additional income. The health, income, environmental, and other benefits of urban agriculture to low-income farmers all make strong positive social contributions (Smit et al., 2006).

According to Gittleman, (2009) the psychological benefits of green space, and gardens in particular, should not be undervalued in discourse on urban ecology. Green space enhances the aesthetic quality of the urban landscape, increasing overall quality of life. Gardens especially can provide a space for meditation and community gathering, and the practice of working with the land is known to be therapeutic.

\subsubsection{Economic benefits}

According to Smit et al. (2006) the economic importance of urban agriculture has received little attention to date. The economic benefits of urban agriculture can be discussed in terms of its role in: Employment, income generation, and enterprise development; the national agriculture sector; and land-use economics. It is not surprising that both low- and high-income entrepreneurs choose urban farming as their industry. Risk is low because food is a basic consumption item with a stable and dependable demand, even during an economic recession. Because they are close to markets, urban farmers can tailor their production to demand and supply high-value and perishable items. Proximity to the market also gives farmers a competitive advantage by saving transportation and storage costs. Whether small or large, legal or illegal, informal or formally recognized, urban farmers around the world are producing competitive incomes through farming. Urban food production has a significant multiplier effect on the urban economy. It generates economic activity in related industries, including those that supply agricultural inputs, as well as storage, transportation, canning, marketing, and food processing.

One major theme of the literature on urban agriculture is the discussion of how it can contribute to the food security and nutrition of cities as a whole, and of the households that are engaged in farming within urban boundaries. One distinction that is often made in the literature refers to the extent to which urban households that engage in agriculture have some degree of market orientation or are purely producing agricultural goods for own-consumption. There seems to be a consensus, based on case study reviews, that the direct food security purpose prevails, but that a substantial number of urban farmers also sell their produce on the market, and more so in Latin America than in Africa (Maxwell, 2003; Ellis and Sumberg, 1998).

\subsubsection{Sustainable urbanization and environmental enhancement}

According to Gittleman (2009) Cities need to close the open loop of resources in, partial consumption, garbage out. In an open-loop system, natural resources, some as inputs to production and some as consumables, are imported into urban areas and the remainder dumped as polluting waste. To improve sustainability, cities and towns must diminish the throughput of resources. A number of definitions of sustainable urbanization have evolved since the 1992 Earth Summit in Brazil. A sustainable city is organized so as to enable its citizens to meet their own needs and to enhance their well-being without damaging the natural world or endangering the living conditions of other people, now or in the future. In most low-income countries, rapid urban population growth and unmanaged expansion are degrading the environment of not only cities, but also their surrounding regions. The result is polluted air, water, and soil; increased temperature; soil erosion; sharply diminished biodiversity; and increased vulnerability to disasters such as floods.

According to Dereje et al., (2007), Mekelle Urban Agricultural Office established specifically to give support to UA producers. It identifies the potential for technical and scientific interventions, but stresses the need to match these to appropriate policy, marketing and education research and intervention. Two key issues which will have to be considered and addressed in any intervention designed for further development of UA are the current land tenure system and the dietary preferences (characterized by low vegetable and fruit consumption) 
prevailing in Ethiopia.

According to Smit et al. (2006) urban agriculture benefits the economy, environment, and well-being of those active in the industry, as well as residents who enjoy its products. It plays a role in programs and projects that target health and nutrition, the environment, enterprise development, income generation, water and sanitation, youth and women, and food production and supply. The current and potential roles of urban agriculture differ from country to country. In countries that must export agricultural products to earn foreign exchange, urban agriculture can feed the cities while rural farmers concentrate on exports. In countries with a fragile ecology, the intensive production technology of urban agriculture and its capacity to absorb urban waste may be essential to averting environmental disasters in urban areas.

\subsubsection{Socio-economic and environmental role of urban agriculture in Africa}

According to Balormakpani and Dinye (2012), conducted a research in Ghana, Urban and peri-urban vegetable farmers generate at least twice the income of their rural colleagues, which is an important contribution to poverty alleviation and better livelihoods. Therefore the contribution of this type of urban agriculture to employment, income generation and better livelihood is unquestionable. Studies conducted by IWMI in 2003 in the three cities revealed that between $40 \%$ and $80 \%$ of urban farmers in Accra, Kumasi and Tamale, consider urban farming as their main income generating activity. At the same time, urban agriculture supplements both diets and incomes of the urban poor, even in confined spaces. The average income from farming may be low but have an enormous impact on household food security. However, it should be realized that, for those whose primary livelihood is farming, income from farming can be appreciable. The importance of this kind of farming especially to urban food security and livelihood of the urban poor is remarkable. For instance, as much as $90 \%$ of lettuce and spring onions eaten in Kumasi and Accra are grown in and around the urban areas.

According to Zezza et al. 2008 in Africa, many of the new jobs needed are for unskilled and relatively uneducated workers, both migrants and those born in the city. With labor forces growing by 2-3\% per year in the fastest urbanizing countries (East and West Africa), thousands of new jobs must be created each year in each of the major cities in those regions. For example, in order to keep the unemployment rate from rising, more than 77,000 jobs in Ouagadougou, and more than 44,000 in Dares Salaam. Partly as a result of the job market lagging behind urban growth, urban poverty and the share of the poor living in cities are rising (IFPRI 1999). These trends have serious implications for food security.

Empirical study conducted in six east and southern cities of Africa, revealed that the number of people obtaining part of their food from urban agriculture is expected to rise from about 25 million to 40 million by 2020 (Renevan, 2006). Dares-salaam, in Tanzania, produces $60 \%$ of milk and $90 \%$ of the vegetable demand of the City (Nugent, 2001). In some cities, urban agriculture has been able to attract the involvement of microenterprises in the production of inputs, processing, packaging and marketing of urban agricultural products. In addition, urban agriculture has contributed significantly towards solving waste management problems by converting urban solid waste into productive agricultural inputs such as compost while treated waste water has been used for irrigation. Urban agriculture is also part of the urban greenery that improves the urban microclimate, increases biological diversity, as well as the aesthetics and recreational functions of urban areas.

The recent world food price crisis has rendered the importance of understanding and confronting the causes of food insecurity of the urban poor even more apparent. Poor urban dwellers, being largely net food buyers and depending mostly on markets for their food supplies, are particularly vulnerable to adverse food price shocks, and are consistently the group in society that suffers most from higher food prices (Zezza et al., 2008; Dessus et al., 2008). Analyzing the extent to which urban agriculture might help shield the urban poor from some of these shocks becomes therefore a topical policy question.

A Study conducted in Addis Ababa by Tewodros (2007) on Livelihood Dependence on Urban Agriculture revealed that cultivating vegetable crops and rearing large cattle are the most common agricultural activities by the urban crop producers and livestock owners, respectively. The former are the most dominant groups among all urban farmers in Addis Ababa. Many urban farmers (40\%) also experience mixed farming in the city. Urban farming in Addis Ababa has significant influence on the livelihoods of urban farmer households as compared to other livelihood options, where over $65 \%$ of the households' income is derived from farming. Besides this, it has equal importance in the livelihoods of both the poor and better-off urban farmers, and contributed to income inequality among the farmers. Vegetable production was found to narrow the income gap between the poor (lowest quintile) and the rich (top quintile) urban farmer households, whereas large cattle production seems to widen the inequality. In addition, the livelihoods of poor urban farmer households are less diversified, and the strategies of the majority $(80 \%)$ are either principally crop farming or non-farm based livelihoods, where as the better-off households follow mostly combinations of farm and non-farm based livelihood strategies. Participations of women and uneducated people in the sector are also widely observed. Similar results were also reported elsewhere such as in Cairo and Dare Salaam, where urban livestock producers generate over $65 \%$ of their income from small livestock rearing in Cairo, and urban agriculture was found to be the second major employment sector in Dare Selaam (Mougeot, 2000). 
Most of the vegetables produced were supplied to the local markets while a relatively small amount was used for home consumption. The study estimated that, given the right support, urban farmers could supply more than $42 \%$ of the vegetable demand in Addis-Ababa. The study found that, in addition to the above economic benefits, urban agriculture in Addis-Ababa was bringing about significant social contributions. It involved some vulnerable groups such as women and the elderly, thereby helping to reduce their dependency on other people. The study established that between 28 and $34 \%$ of urban farmers were female, while $43 \%$ were elderly. Urban agriculture also served to strengthen social integration of the farmers by organizing them into cooperatives. However, the study found that the number of female farmers was less than their male counterparts. This finding confirmed previous studies carried out by (Tewodros, 2007).

According to Mpofu (2013) urban agriculture in Addis-Ababa has been its capacity to generate income and create employment opportunities. On average, three vegetable growing cooperatives gained an annual income of 157,005.31 Birr, giving an average monthly income of 581.00 Birr per each member of the cooperative. This was equivalent to the middle income of group in Ethiopia. In terms of employment, the study found that there were about 16,000 people engaged in producing vegetables in Addis Ababa. Out of these, about 7,454 families were organized into 11 farmer's cooperatives. The study identified 957 vegetable farmers with a total family size of about 7,454 people. Thus, it could be said that the sector secured permanent and/or part-time employment for around 5,057 household heads or 27,954 members of their families. The study found that there were a number of multiplier effects emanating from urban agriculture. The study classified these into compost production and processing, and packaging and marketing of urban agricultural products. However, the study concluded that the compost produced from the organic waste was quite insignificant compared to the amount of organic waste generated in the City.

\subsubsection{Determinants of urban agriculture in Africa}

The more frequent argument from urban planning is that agriculture should be confined to rural areas, as it can interfere with more productive use/rent of land by other economic activities. Those against are saying, UA hampers urban development, threatens public health, has negative environmental impacts, is not very profitable, and city governments in developing countries do not have capacities and means to manage it adequately. Despite limited support and heavy losses, UA is generating products valued in the tens of Millions of USD, year in and year out, in major LDC urban centers. UA is comparatively affordable, a noteworthy source of income and savings and is more profitable than rural-based production. The up and downstream effects of UA in the local economy are largely unknown and could be considerable. There is little literature overtly condemning UA under any form; opposition has tended to come more from urban planning, public health and environmental circles than from agencies covering employment, community services and agriculture. Governmental checks and balances exist and have been applied to a limited extent. Regulations have remained largely ineffective and must be revised, priorised and implemented in an appropriate and participatory way; they need to be enabling. Concern over agrochemical use in UA tends to be exaggerated; actual use and related problems are limited by various factors, particularly in the case of intra-urban, home-based, Women-practiced, food self-provisioning. More information seems to exist on evidence and on Measures to curb public health risks posed to UA by ambient factors, as opposed to risks introduced by UA into the urban environment. Still, the latter is a source of rising governmental concern. In both cases problems are technically manageable; however, this depends on cities Making better use of prevention and mitigating measures, including trans-sectoral coordination (waste management) and the use of UA to enhance environmental quality (Mougeot, 1994).

According to Balormakpani and Dinye (2012), conducted a research in Ghana, the main constraints found out from this study was that there was no conscious planning for informal businesses such as urban agriculture in Kumasi as it has not been integrated into the land use plans of the city, lack of financial support, grazing of crops by animals and problems of access to land are the key challenges of urban farmers. Those involved in urban agriculture are mostly men in food crop farming and female in vegetable cultivation.

According to Mpofu (2013) among the most critical challenges that were identified by the study and confirmed by vegetable producers were lack of credit; high interest rates; and, poor supply of inputs. About $89.9 \%$ of the selected cooperatives and $90 \%$ of individual farmers stated that they experienced difficulties whenever they needed credit to expand and modernize their operations. Similarly, although the Addis Credit and Savings Microfinance Institution had expanded their services to ten sub-cities in Addis Ababa, their high interest rates remained a stumbling block to urban farmers. As if this was not enough, the newly opened special branch of the Development Bank of Ethiopia had not yet made its position clear regarding credit access by the urban farmers.

A Study conducted in Addis Ababa by Tewodros (2007) on Livelihood Dependence on Urban Agriculture revealed that low land productivity, lack of education (especially for household heads), livestock and credit were the critical assets that distinguished the poor from better-off urban farmer households, and they seemed to limit the productivities of the poor even though the households have better adult work forces.

According to Mougeot (2001), lack of positive government policy on and recognition of urban agriculture 
as a viable sector are prevalent in most developing countries. Most policies on agriculture, food, health, nutrition and environmental policies are silent on urban agriculture. Lack of official recognition of urban agriculture often leads to a feeling of insecurity among urban farmers, thereby limiting their commitment to investment in this sector. Similarly, some credit agencies, researchers, development agencies and market agents generally do not view urban agriculture as a significant industry (UNDP, 1996). As a consequence, the sector's benefits are not being fully realized by those urban populations who require nourishment.

According to Drescher et al. (1999), the most critical institutional constraints to urban agriculture include lack of access to farming land as well as to farming inputs such as seeds, fertilizer, pesticides, and implements. Urban food markets are often designed, sometimes since colonial times, to import food from rural areas, while the input producing businesses are also oriented towards serving rural agriculture.

Thus, both the input and output market systems and infrastructure often favor rural agriculture (UNDP, 1996). This is largely because the market structures tend to be composed of large wholesalers who purchase directly from rural areas or from intermediary wholesale markets at the edge of the city. Thus, generally, smaller urban farmers do not yet fit well into these structures. Some other problems commonly experienced by urban farmers include loss of vegetables to theft due to inadequate police protection. This is because urban agriculture, unlike most other industries, produces mostly in the open and is thus particularly vulnerable to theft (Smit et al., 1996).

Key areas requiring attention include the opportunities for and risks of accessing and recycling accumulated urban nutrients (Dubbeling et al. 2005); the need to adapt and intensify production in space constrained conditions (van Veenhuizen 2003); the risks of exposure to urban contaminants (Cole et al. 2004); the opportunities for agro-enterprises and accessing diverse nearby markets (Holmer 2001; Peters. et al. 2002); and the need to engage with a dense and often intrusive regulatory, policy and planning environment, which impinges on agriculture in multiple ways and makes demands on the types of technologies that can be used (Dubbeling 2001).

\subsection{Promoting Urban Food Production}

To enable a successful farming activity in the urban area, there should be an amiable and a sound urban economy that is stable. Policies that encourage citizens especially the poor to engage in it must be considered. There is therefore, the need to establish such an environment to allow for the execution of urban agriculture to help reduce poverty (Balormakpani and Dinye, 2012).

\subsection{1. bridging the financial gap}

Finance remains a real obstacle for many urban poor farmers. The ability to secure funds for investment in general has been a battling case. Urban farmers invest in inputs for production such as labor, land, seeds, fertilizers and other needed resources continuously but only earn after the harvest period. They mostly do not have access to credit facilities, savings or remittances to provide for their inputs. The state-operated activities, such as targeted agricultural finance schemes and input schemes operated by parastatal marketing organizations, has not worked effectively. The use of microfinance schemes and other models to enable the accessibility of the urban poor to financial assistance are gaining grounds through Non-Governmental Organizations. A lack of market power can also be addressed if local governments encourage access to credit for small farmers. Currently, little or no credit is available because no collateral is offered and/or because urban farmers are poor women both major impediments to gaining credit. As a result, if the small farmer works with a market trader to sell produce, she is often obliged to accept short-term credit from that person on terms that might be disadvantageous to her (Van den Berg 1997). The purpose of small loans is to acquire additional capital or seeds or even as an advance on production to meet cash-flow needs of the household.

\subsubsection{Taking advantage of technology}

Technology is central to accelerating urban agricultural growth and informal businesses. The use of innovative and technological systems of operations in urban agriculture will help improve productivity and production and manage resource. Realizing the benefits of technology and innovation will require; working with poor urban farmers to identify and tackle their key problems; concerted efforts to develop a range of new technologies and practices and systems that enable farmers to hear about, choose from and obtain appropriate new and existing technologies (Van den Berg 1997). There is therefore, the need for an efficient system of publicly funded agricultural research at both the national and international levels.

\subsubsection{Creation of a research center}

To actualize the capable role of urban farming in reducing urban poverty government should create a research and information center for urban agriculture. Government should fund research activities into safe urban agriculture practices and make the information available to all farmers. Consumer preference information can also be communicated to farmers to enable them meet the market demands. The dissemination of such information can be channeled through the media: radio stations, television station, extension and veterinary service officers (Balormakpani and Dinye, 2012). 


\subsubsection{Provision of public services at the micro level}

Balormakpani and Dinye (2012) at the micro level of the household, policies should also be oriented toward efficient and timely provision of services which the market fails to provide, or where there is a public-good component. For instance, providing accurate market information at the level of the individual farmer can be instrumental in clarifying incentives for farmer choices, such as commodity selection and timing of production. Government authorities can also provide technical support and training through extension services geared to the needs of urban farmers, and help farmers become well-versed in the preferences of the urban consumer.

\subsubsection{Policies related to infrastructure}

Infrastructure is defined for this section to include physical and informational facilities, which are most often provided by public authorities because their benefits have the nature of being public goods. It also includes other municipal services normally provided by public authorities. These services and facilities together determine the nature and efficacy of a city government's activities and are paramount in contributing toward the live ability of a city (Drechsel \& Kunze 1999).

\subsubsection{Public infrastructure and land-use planning}

The infrastructure and land-use policies needed by urban farmers are scarcely different from those that support other industries. Farmers need safe and adequate transportation for goods and people, including a well-planned road system between the farming land and residential areas and road linkages between rural and urban areas. They also need reliable public utility services (water, wastewater with appropriate level of treatment for re-use, waste collection and disposal, and electricity). Finally, they need land-use regulations and planning that allows proximity of needed services and inputs at reasonable price s(Drechsel \& Kunze 1999).

\subsubsection{Markets and information systems}

A lack of knowledge among small-scale urban farmers impedes their access to markets or prevents them from producing for markets, even when it could be lucrative to do so. This can happen because small producers are not welcome at established markets, or because they do not know what consumers prefer or what prices their products would obtain in the official market. They also have little training or time to assure the quality of their products, often only primitive means of packaging and transporting to market, and little choice among market outlets (Drechsel \& Kunze 1999). As a result, most small farmers are more oriented toward providing supplementary food for their families, rather than investigating the potential returns from the resources they put into farming (Van den Berg 1997).

\subsection{What Future for Urban Agriculture?}

A paper commissioned by IDRC points to several trends which are likely to expand and transform UA well into the established sector. Most of these trends are underway and provide vectors which can be better managed through appropriate policy changes For instance, lower density urban expansion will increase land opportunities for interim or permanent UA, particularly in Africa. This will continue to compete and outrun RA in certain crop lines as improved UA technologies spread to other production systems (aquiculture. small livestock, hydroponics, specialty crops for niche markets). UA will be accepted and implemented more systematically as a major intervention in food security and social security programs, and environmental agencies and programs will also include more UA. Urban waste will be more commonly applied as a production input, as home and communitybased treatment of waste outperform massive and non-selective disposal systems. Information and communication technologies will enable small producers and processors to access and share prompt and reliable technical and market information, credit, and to organize into virtual corporations. Community and civic organizations will increasingly support UA and women will continue to dominate the industry. As women inexorably achieve greater legal and financial rights, UA will grow quickly (Smit et al., 1996).

Veenhuizen (2006) in his book stated that a growing number of cities are designing policies and programmes on urban agriculture, applying multi-stakeholder planning approaches to identify effective ways to integrate urban agriculture into urban sector policies and urban land use planning and to facilitate the development of safe and sustainable urban agriculture. These aim at fostering the multiple functions of urban agriculture. There is a need however to explore the relationship between multi-functionality and sustainability of urban agriculture. This involves the analysis of both positive and negative environmental functions as well as their compound effect. Areas for further research and development include: land tenure, legislation and urban land use planning; gender; methodologies in working with stakeholders, such as action research with urban farmers or with planners to include agriculture in environmental planning, as a part of green belts, city parks and open spaces; development of new institutions or institutional arrangements such as urban and peri-urban markets and support to (commercial and subsistence) horticulture, aquaculture and livestock systems. Facilitating such research and development requires the creation of adequate institutional frameworks that give urban agriculture an institutional home and ensure the active participation of direct and indirect stakeholders in the formulation and implementation of urban agriculture policies and action programmes. When accepted and facilitated, urban agriculture will be sustainable, maintaining its dynamism and flexibility, adapting to changing urban conditions 
and demands, intensifying its productivity and diversifying its functions for the city, whilst reducing associated health and environmental risks and by doing so gaining more social and political acceptability. In certain parts of a city, the existing forms of urban agriculture may fade away or change its form and functions drastically, while new forms of urban agriculture may develop in other parts of that same city. On the longer term, urban agriculture will be sustainable especially if its potential for multifunctional land use is recognized and fully developed. The sustainability of urban agriculture is strongly related to its contributions to the development of a sustainable city: an inclusive, food-secure, productive and environmentally-healthy city.

\subsection{Conclusion}

This literature review has focused on the socio-economic and environmental role of urban agriculture. It also reviewed major constraints and important means to overcome those challenges. Future outlook of urban agriculture was also reviewed to oversee the coming fate of this sector. As cities expand in size and population, competition is been created between the traditional land uses and new emerging land uses and land uses that bid higher prices and those that offer less price such as urban agriculture. Even though this contradictory view has been there urban agriculture pays a key role in poverty reduction. Farming in the world's cities and towns is increasingly turning to be a vital part of the economy, especially in developed countries.

Despite this, state interventions, public policies and planning have failed to incorporate it especially in some Africa cities. In spite of this, urban agriculture has the capacity to thrive well in towns if given the needed support. Urban agriculture normally has numerous functions in terms of time and space, as well as social like women and low income groups and economic like financial crisis, food shortage conditions. As a result of the numerous importances government should initiate programmes in support of urban agriculture. The time has come to start integrating urban agriculture into urban planning. Urban agriculture is also part of the urban greenery that improves the urban micro-climate, increases biological diversity, as well as the aesthetics and recreational functions of urban areas.

From the above empirical review the principal limit factor for urban farmers and gardeners were difficult access to land, lack of experience, Lack of financial support, grazing of crops by animals and theft of farm products, Low land productivity, lack of training, access to credit facilities and high interest rates. The stateoperated activities, such as targeted agricultural finance schemes and input schemes operated by parastatal marketing organizations, has not worked effectively.

\subsection{Recommendations}

On the basis of the above review and conclusions, the paper recommends that the Cities administrations should change its mind-set and see urban agriculture as a viable sector that could contribute to food security and nutrition of the urban dwellers. In labor-rich but capital poor countries such as Africa, urban agriculture should, therefore, be encouraged, strengthened and given recognition in urban planning and development. Top among the requirements to stimulate this sector, is the need for an urban agricultural policy, at both national and City levels.

$>$ Technical advice and training for farmers by agriculture extension officers should be offered and should be sustained.

$>$ The establishment of farmers' markets and related basic infrastructure

$>$ The stimulation of micro-enterprise development in food processing and marketing

$>$ Improving access of urban farmers to credit services and technical advice will be the focus in issue

$>$ Municipalities should try to reduce the number of urban poor and promote their social integration in the urban economy, while many national level policies tend to push people into the informal sector.

$>$ To enable a successful farming activity in the urban area, there should be an agreeable and a sound urban economy that is stable.

$>$ Policies that encourage citizens especially the poor to engage in it must be considered.

\section{REFERENCES}

Abubakari Ahmed Balormakpani and Romanus D. Dinye 2012 Assessing the Informal Sector in Kumasi: Case of Elements of Urban Agriculture.pp 198-200.

Alberto Zezza , Luca Tasciotti 2010 Urban agriculture, poverty, and food security: Empirical evidence from a sample of developing countries. p 56

Armar-Klemesu, M., 2001. Urban agriculture and food security nutrition and health. Thematic paper 4. In: Bakker, N. et al. (Eds.), Growing Cities, Growing Food: Urban Agriculture on the Policy Agenda. DSE, Fefdafing. Pp 157-169

Armar-Klemeu M \& Maxwell D. 2006. Accra: urban agriculture as an asset strategy, supplementing income and diets. Pp 74-78

Bakker, N, Pablo, TL, Sanchez, LMR, 2001. Growing cities, growing food: urban agriculture on the policy 
agenda. Feldafing Press.

Bryceson D.F. and D. Potts, 2005. African Urban Economies: Viability, Vitality or Vitiation. P. Macmillan. London.

Cole, D.C., K. Bassil, H. Jones-Otazo, and M. Diamond. 2004. Health risks and benefits associated with UPA: impact assessment, risk mitigation and healthy public policy. Workshop on Health Risks and Benefits of Urban \& Peri-Urban Agriculture (UPA) including Livestock Production in Sub-Saharan Africa, ILRI, Nairobi,

Dereje Ashebir a, Margaret Pasquini b, and Wubetu Bihon a 2007 Urban agriculture in Mekelle, Tigray state, Ethiopia: Principal characteristics, opportunities and constraints for further research and development

Drechsel P \& Kunze D. 1999. Synopsis from International Workshop on Urban and Peri-Urban Agriculture: Closing the Nutrient Cycle for Urban Food Security and Environmental Protection, Accra. Text available at www.CityFarmer.org.

Drescher, A.W, 1999. "Urban Microfarming in Central Southen Africa: A Case Study of Lusaka, Zambia." African Urban Quarterly (May-August 1996) 11/2-3: 229-248.

Dubbeling, M., G. Prain, M. Warnaars and T. Zschocke, 2005. Feeding cities in anglophone Africa with urban agriculture: concepts, tools and case studies for practitioners, planners and policy makers.

Egziaber, A.G., Lee-Smith, D., Maxwell, D.G., Memon, P.A., Mougeot, L.J.A., Sawio, C.J., 1994. Cities Feeding People. An Examination of Urban Agriculture in East Africa. IDRC, Ottawa

Ellis, F., Sumberg, J., 1998. Food production, urban areas and policy response. Food Policy 26 (2), 213-225.

ENDA-Ethiopia, 2002. Experience of Urban Agriculture in Addis-Ababa, Addis-Ababa, Ethiopia.

Getachew, Y, 2002. The living garden: a bio-intensive approach to urban agriculture in Ethiopia.

Henk De Zeeuw, 2003, Annotated Bibliography On Urban Agriculture Prepared For The Swedish International Development Agency (Sida). Pp.7-8

Holmer, R., 2001. Appropriate methods for micro-enterprise development in urban agriculture. Urban Agriculture Magazine 5: 51-53

Mara Gittleman 2009 The Role of Urban Agriculture in Environmental and Social Sustainability: Case Study of Boston Tufts University American Studies

Maxwell, D., 2003. The importance of urban agriculture to food and nutrition. In: Annotated Bibliography on Urban Agriculture. Sida and ETC, Leusden, The Netherlands, pp. 22-129.

Maxwell, D., Levin, C., Csete, J., 1998. Does urban agriculture help prevent malnutrition? Evidence from Kampala. Food Policy 23 (5), 411-424.

Ministry of Finance and Economic Development for Ethiopia, 2010/11, Ethiopia's Progress towards Eradicating Poverty: An Interim Report on Poverty Analysis Study

Mougeot, Luc J.A., 1994 "Urban Food Production: Evolution. Official Support and Significance." Cities Feeding People Report. International Development Research Centre, Ottawa.

Mougeot, Luc J.A., 2000 Urban Agriculture: Definition, Presence, Potentials and Risks, and Policy Challenges, International Development Research Centre (IDRC)

Mudimu G.D. 1996. Urban agricultural activities and women's strategies in sustaining family.

Nugent, R., 2001. The impact of urban agriculture on household and local economies. Thematic paper 3. In: Bakker, N. et al. (Ed.), Growing Cities, Growing Food: Urban Agriculture on the Policy Agenda. DSE, Fefdafing.

Peters, D., C. Wheatley, G. Prain, J. Slaats and R. Best. 2002. Improving agro enterprise clusters: root crop processing and piglet production clusters in peri-urban Hanoi. In: Local Agrifood Systems: Products, Enterprises and Local Dynamics. Montpellier: CIRAD.

René van Veenhuizen 2006 ETC - Urban Agriculture Cities Farming for the Future Urban Agriculture for Green and Productive Cities.

René van Veenhuizen, 2012 RUAF Foundation the Role of Urban Agriculture in building resilient cities

Smit, J. and M. Bailkey. 2006. Urban agriculture and the building of communities. In: Veenhuizen, R van (ed), Cities farming for the future; urban agriculture for green and productive cities, ETC, IIRR and IDRC, Manila, pp 145-159.

Smit, J. and M. Bailkey. 2006. Urban agriculture and the building of communities. In: Veenhuizen, R van (ed), Cities farming for the future; urban agriculture for green and productive cities, ETC, IIRR and IDRC.

Smit, Jac (1996) Urban Agriculture: Progress and Prospect: 1975-2005. Cities Feeding People Report 18. international Development Research Centre, Ottawa.

Staal, Steven J. (1997) "Potential Impacts of Periurban Dairying on Smallholder African Producer Households and Communities." Draft background note for discussion. International Livestock Research Institute, Nairobi. September.

Thomas P. Z. Mpofu 2013 An evaluation of the performance of urban agriculture in Addis-Ababa City, Ethiopia Faculty of Science and Technology, pp 124-130 
Tewodros Firdissa Duressa, Livelihood Dependence on Urban Agriculture in Addis Ababa, Ethiopia,pp 25-28

UNDP, 1996. Urban Agriculture. Food, Jobs, and Sustainable Cities. United Nations Development Programme. Publication Series for Habitat II, vol. 1. UNDP, New York.

UN-HABITAT (2006): State of the World's Cities Report 2006-2007, the: The Millennium Development Goals and Urban Sustainability.

Zezza, A., Azzarri, C., Davis, B., Covarrubias, K., Tasciotti, L., Anriquez, G., 2008. The Impact of Rising Food Prices on the Poor. FAO-ESA Working Paper 08-07 